\title{
Values of detection of NF-kB activation level combined with IL-6 and TNF- $\alpha$ levels in peripheral neutrophils in the prediction of multiple organ dysfunction syndrome in patients with severe multiple trauma
}

\author{
JIE ZENG \\ Department of Emergency Surgery, Sichuan Provincial People's Hospital, Chengdu, Sichuan 610072, P.R. China
}

Received December 28, 2017; Accepted June 1, 2018

DOI: $10.3892 /$ etm.2018.6472

\begin{abstract}
The aim of this study was to analyze the dynamic changes and predictive values of nuclear factor $-\kappa \mathrm{B}(\mathrm{NF}-\kappa \mathrm{B})$ combined with interleukin-6 (IL-6) and tumor necrosis factor- $\alpha$ $(\mathrm{TNF}-\alpha)$ in peripheral blood in multiple organ dysfunction syndrome (MODS) in patients with severe multiple trauma. Seventy patients diagnosed with severe multiple trauma in Emergency Department of Sichuan Provincial People's Hospital (Chengdu, China) from April 2014 to April 2016 were selected and retrospectively analyzed. The patients enrolled were divided into the MODS group $(n=25)$ and the non-MODS group ( $\mathrm{n}=45)$. The injury severity scores (ISSs), acute physiology and chronic health evaluation II (APACHE II) scores, NF- $\kappa \mathrm{B}$, IL- 6 and TNF- $\alpha$ levels in patients were detected at different time points (12, 24 and $48 \mathrm{~h}$ after admission), the changes in different indexes and the areas under the receiver operating characteristic (ROC) curve (AUC) were analyzed. The predictive values of different detection methods in MODS patients were discussed and compared. The ISS, APACHE II score, NF- $\kappa$ B, IL- 6 and TNF- $\alpha$ levels in the MODS group at admission and 24 and $48 \mathrm{~h}$ after admission were higher than those in the non-MODS group $(\mathrm{P}<0.05)$. Those indexes in the deceased patients at 12,24 and $48 \mathrm{~h}$ after admission were higher than those in survivors $(\mathrm{P}<0.05)$. The ISS, APACHE II score, NF- $\kappa$ B, IL- 6 and TNF- $\alpha$ levels were not the risk factors of MODS in patients with severe multiple trauma $(\mathrm{P}>0.05)$. AUCs of ISS $>22$ points and APACHE II score $>14$ points in predicting MODS were lower than that of combined detection of $N F-\kappa B>1.20$. In conclusion, the combined detection of NF- $\kappa$ B, IL- 6 and TNF- $\alpha$ in peripheral blood of patients with acute multiple trauma is more helpful to predict the occur-
\end{abstract}

Correspondence to: Dr Jie Zeng, Department of Emergency Surgery, Sichuan Provincial People's Hospital, 32 Xierduan Yihuan Road, Chengdu, Sichuan 610072, P.R. China

E-mail: youbang0920@163.com

Key words: acute multiple trauma, MODS, ISS, APACHE II score, $\mathrm{NF}-\kappa \mathrm{B}, \mathrm{IL}-6, \mathrm{TNF}-\alpha$ rence of MODS, which has a certain guiding significance for the prognosis of patients with MODS.

\section{Introduction}

Acute multiple trauma is a common disease in clinic, especially in emergency rescue, which will not only develop more rapidly, but also greatly increase the mortality rate if it occurs or is complicated by multiple organ dysfunction syndrome (MODS), causing adverse effects on the prognosis (1). Numerous studies have shown that when patients suffer from acute multiple trauma, the inflammation out of control will lead to the occurrence of MODS, namely the unbalance between inflammatory response system composed of immune inflammatory cells and tissues and anti-inflammatory response system, among which immune inflammatory cells play key roles (2). At present, finding a detection method that can predict MODS quickly and effectively is a common problem $(3,4)$. Many MODSs are developed from systemic inflammatory response syndrome (SIRS); nuclear factor- $\kappa \mathrm{B}(\mathrm{NF}-\kappa \mathrm{B})$ in neutrophils is a mediator involved in the genetic transcription and regulation of inflammatory factors, while interleukin-6 (IL-6) is one of the common factors leading to inflammation (5). When the body is exposed to pathogenic factors, a variety of cells in the body can be induced to produce cytokines, such as macrophages and Kupffer cells. The most common cytokines of MODS are tumor necrosis factor (TNF), IL, among which TNF- $\alpha$ occupies a major position. The injection of high-dose TNF- $\alpha$ into the human body can induce the occurrence of SIRS, eventually leading to MODS $(6,7)$. Therefore, the occurrence of MODS in patients with acute multiple trauma was predicted in this study through detecting the NF- $\kappa \mathrm{B}, \mathrm{IL}-6$ and TNF- $\alpha$ levels in peripheral blood, helping the clinical diagnosis and treatment.

\section{Materials and methods}

General data. A total of 70 patients diagnosed with severe multiple trauma in Emergency Department of Sichuan Provincial People's Hospital (Chengdu, China) from April 2014 to April 2016 were selected and retrospectively analyzed. The patients enrolled were divided into the MODS group $(n=25)$, including 18 males and 7 females with an average of 
Table I. Comparisons of general data between the two groups.

\begin{tabular}{|c|c|c|c|c|c|c|}
\hline Groups & $\mathrm{n}$ & Male/female & $\begin{array}{c}\text { Age } \\
\text { (years) }\end{array}$ & $\begin{array}{l}\text { Drinking } \\
(\mathrm{n} / \%)\end{array}$ & $\begin{array}{c}\text { Smoking } \\
\text { history }(\mathrm{n} / \%)\end{array}$ & $\begin{array}{c}\text { Chronic disease } \\
\text { history }(\mathrm{n} / \%)\end{array}$ \\
\hline Non-MODS & 45 & $28 / 17$ & $33.8 \pm 8.5$ & $25(55.6 \%)$ & $27(60.0 \%)$ & $8(17.8 \%)$ \\
\hline MODS & 25 & $18 / 7$ & $34.6 \pm 7.6$ & $13(52.0 \%)$ & $14(56.0 \%)$ & $5(20.0 \%)$ \\
\hline P-value & & 0.812 & 0.765 & 0.312 & 0.297 & 0.498 \\
\hline
\end{tabular}

$\mathrm{P}>0.05$, the difference is not statistically significant.

Table II. Comparisons of ISS, APACHE II score, NF- $\kappa$ B, IL-6 and TNF- $\alpha$ levels at admission between the two groups.

\begin{tabular}{lcccccc}
\hline Groups & $\mathrm{n}$ & $\mathrm{ISS}$ & APACHE II score & NF- $\mathrm{BB}$ & IL-6 $(\mu \mathrm{g} / \mathrm{l})$ & $\mathrm{TNF}-\alpha(\mathrm{ng} / \mathrm{ml})$ \\
\hline Non-MODS & 45 & $18.3 \pm 2.8$ & $11.9 \pm 2.6$ & $1.0 \pm 0.3$ & $23.2 \pm 4.6$ & $1.96 \pm 0.23$ \\
MODS & 25 & $22.6 \pm 3.9$ & $18.2 \pm 3.2$ & $1.4 \pm 0.2$ & $35.3 \pm 3.8$ & $3.62 \pm 0.21$ \\
P-value & & $<0.001$ & $<0.001$ & $<0.001$ & $<0.001$ & $<0.001$ \\
\hline
\end{tabular}

34.6 \pm 7.6 years old, and the non-MODS group $(n=45)$, including 28 males and 17 females with an average of $33.8 \pm 8.5$ years old. The histories of drinking, smoking and chronic diseases of all patients were collected. There were no statistically significant differences in general data and past medical history between the MODS and non-MODS groups ( $\mathrm{P}>0.05)$, and the data were comparable (Table I). Inclusion criteria: patients diagnosed with severe multiple trauma; patients aged above 14 years old; patients admitted within $6 \mathrm{~h}$ after trauma. Exclusion criteria: patients receiving glucocorticoid or immunosuppressive therapy at admission; patients aged below 14 years old; patients with severe liver or kidney disease, heart disease, cardiogenic shock or cancer; pregnant women; patients with incomplete clinical data or who quit halfway. The study was approved by the Ethics Committee of Sichuan Provincial People's Hospital (Chengdu, China) and written informed consents were signed by the patients and/or guardians.

Methods. The injury severity scores (ISS), acute physiology and chronic health evaluation II (APACHE II) scores, NF- $\kappa \mathrm{B}$, IL- 6 and TNF- $\alpha$ levels in patients enrolled were detected at different time-points (12, 24 and $48 \mathrm{~h}$ after admission). Peripheral venous blood $(8 \mathrm{ml})$ after anticoagulation was collected at different time points, and the serum was separated and stored at $-80^{\circ} \mathrm{C}$ for standby application. 1) The level of $\mathrm{NF}-\kappa \mathrm{B}$ was detected via electrophoretic mobility shift assay (EMSA). After specimen collection, the nucleoprotein was extracted using the nucleoprotein extraction kit provided by Active Motif (Carlsbad, CA, USA), and the activity of nucleoprotein was detected via enzyme-linked immunosorbent assay (ELISA). The optical density (OD) at the wavelength of $500 \mathrm{~nm}$ was measured using the kit provided by Active Motif. 2) Detection of IL- 6 and TNF- $\alpha$ levels: The peripheral IL- 6 and TNF- $\alpha$ specimens were centrifuged at 1,800 x g for $20 \mathrm{~min}$, and the upper-layer serum was collected. The nucleoprotein was collected via ELISA and placed into the solubilizing buffer; after incubation and washing for many times, the goat anti-rabbit horseradish peroxidase (HRP)-labeled polyclonal antibody (dilution, 1:1,000; cat no. 7074; Cell Signaling Technology, Danvers, MA, USA) was added, and the mixture was incubated and washed again. Finally, the IL- 6 and TNF- $\alpha$ levels were detected using the Bio-Rad 680 microplate reader provided by Active Motif, and OD at the wavelength of $450 \mathrm{~nm}$ was measured. All of the above indexes were measured by professional detection physicians in strict accordance with the manufacturer's instructions.

Statistical analysis. Statistical Product and Service Solutions (SPSS) 19.0 software (SPSS, Inc., Chicago, IL, USA) was used for data processing. Data were collected and presented as mean $\pm \mathrm{SD}$, ANOVA was used for the comparison between multiple groups and the post hoc test was the Least Significant Difference test. Multivariate logistic regression analyses were performed for the factors with statistically significant difference, and the area under the receiver operating characteristic (ROC) curve (AUC) was calculated. $\mathrm{P}<0.05$ was considered to indicate a statistically significant difference.

\section{Results}

Comparisons of ISS, APACHE II score, NF- $\kappa B, I L-6$ and TNF- $\alpha$ levels at admission between the two groups. The peripheral serum was collected from patients at $12 \mathrm{~h}$ after admission to detect the serum NF- $\kappa \mathrm{B}$, IL- 6 and TNF- $\alpha$ levels. The ISS, APACHE II score, NF- $\kappa$ B, IL- 6 and TNF- $\alpha$ levels in the MODS group were higher than those in the non-MODS group, and the differences were statistically significant $(\mathrm{P}<0.05)$ (Table II).

Comparisons of ISS, APACHE II score, NF- $\kappa B, I L-6$ and TNF- $\alpha$ levels at different time points $(12,24$ and $48 \mathrm{~h}$ after admission) between the two groups. The ISSs, APACHE II scores, NF- $\kappa$ B, IL- 6 and TNF- $\alpha$ levels in the MODS group at 12, 24 and $48 \mathrm{~h}$ after admission were higher than those in 
Table III. Comparisons of ISS, APACHE II score, NF- $\mathrm{KB}$, IL-6 and TNF- $\alpha$ levels at different time-points after admission between the two groups.

\begin{tabular}{|c|c|c|c|c|c|c|}
\hline Groups & $\mathrm{n}$ & ISS & APACHE II score & $\mathrm{NF}-\kappa \mathrm{B}$ & IL-6 $(\mu \mathrm{g} / 1)$ & $\mathrm{TNF}-\alpha(\mathrm{ng} / \mathrm{ml})$ \\
\hline Non-MODS & 45 & & & & & \\
\hline $12 \mathrm{~h}$ after admission & & $18.3 \pm 2.8$ & $11.9 \pm 2.6$ & $1.0 \pm 0.3$ & $23.2 \pm 4.6$ & $1.96 \pm 0.23$ \\
\hline $24 \mathrm{~h}$ after admission & & $21.6 \pm 3.2$ & $14.2 \pm 3.1$ & $1.2 \pm 0.2$ & $26.5 \pm 4.9$ & $2.22 \pm 0.32$ \\
\hline $48 \mathrm{~h}$ after admission & & $23.2 \pm 2.7$ & $15.9 \pm 2.9$ & $1.3 \pm 0.3$ & $28.2 \pm 3.4$ & $2.91 \pm 0.41$ \\
\hline MODS & 25 & & & & & \\
\hline $12 \mathrm{~h}$ after admission & & $22.6 \pm 3.9^{\mathrm{a}}$ & $18.2 \pm 3.2^{\mathrm{a}}$ & $1.4 \pm 0.2^{\mathrm{a}}$ & $35.3 \pm 3.8^{\mathrm{a}}$ & $3.62 \pm 0.21^{\mathrm{a}}$ \\
\hline $24 \mathrm{~h}$ after admission & & $29.3 \pm 4.2^{\mathrm{a}, \mathrm{b}}$ & $25.3 \pm 2.7^{\mathrm{a}, \mathrm{b}}$ & $1.9 \pm 0.2^{\mathrm{a}, \mathrm{b}}$ & $41.6 \pm 4.1^{\mathrm{a}, \mathrm{b}}$ & $4.93 \pm 0.24^{\mathrm{a}, \mathrm{b}}$ \\
\hline $48 \mathrm{~h}$ after admission & & $36.5 \pm 3.6^{\mathrm{a}, \mathrm{c}}$ & $29.9 \pm 2.3^{\mathrm{a}, \mathrm{c}}$ & $2.3 \pm 0.3^{\mathrm{a}, \mathrm{c}}$ & $49.3 \pm 3.7^{\mathrm{a}, \mathrm{c}}$ & $5.71 \pm 0.31^{\mathrm{a}, \mathrm{c}}$ \\
\hline
\end{tabular}

${ }^{\mathrm{a} C o m p a r e d}$ wtih the non-MODS group; ${ }^{\mathrm{b}}$ compared with 12 after admission; ${ }^{\mathrm{c}}$ compared with $24 \mathrm{~h}$ after admission. $\mathrm{P}<0.05$, the difference is statistically significant.

Table IV. Comparisons of ISS, APACHE II score, NF-kB, IL-6 and TNF- $\alpha$ levels at different time-points after admission between the deceased and survivor.

\begin{tabular}{|c|c|c|c|c|c|c|}
\hline Groups & $\mathrm{n}$ & ISS & APACHE II score & $\mathrm{NF}-\kappa \mathrm{B}$ & IL-6 $(\mu \mathrm{g} / \mathrm{l})$ & TNF- $\alpha(\mathrm{ng} / \mathrm{ml})$ \\
\hline Deceased & 19 & & & & & \\
\hline $12 \mathrm{~h}$ after admission & & $25.3 \pm 2.9^{\mathrm{a}}$ & $29.5 \pm 3.5^{\mathrm{a}}$ & $1.5 \pm 0.2^{\mathrm{a}}$ & $29.3 \pm 4.6^{\mathrm{a}}$ & $4.66 \pm 0.25^{\mathrm{a}}$ \\
\hline $24 \mathrm{~h}$ after admission & & $26.5 \pm 2.6^{\mathrm{a}, \mathrm{b}}$ & $32.3 \pm 4.1^{\mathrm{a}, \mathrm{b}}$ & $1.8 \pm 0.2^{\mathrm{a}, \mathrm{b}}$ & $35.3 \pm 3.9^{\mathrm{a}, \mathrm{b}}$ & $4.93 \pm 0.31^{\mathrm{a}, \mathrm{b}}$ \\
\hline $48 \mathrm{~h}$ after admission & & $28.3 \pm 1.9^{\mathrm{a}, \mathrm{c}}$ & $33.6 \pm 3.3^{\mathrm{a}, \mathrm{c}}$ & $2.1 \pm 0.3^{\mathrm{a}, \mathrm{c}}$ & $45.9 \pm 4.2^{\mathrm{a}, \mathrm{c}}$ & $5.63 \pm 0.22^{\mathrm{a}, \mathrm{c}}$ \\
\hline Survivor & 51 & & & & & \\
\hline $12 \mathrm{~h}$ after admission & & $19.5 \pm 3.2$ & $18.3 \pm 4.4$ & $1.0 \pm 0.1$ & $24.4 \pm 5.1$ & $1.72 \pm 0.36$ \\
\hline $24 \mathrm{~h}$ after admission & & $20.8 \pm 2.9$ & $19.6 \pm 3.9$ & $1.2 \pm 0.2$ & $26.3 \pm 4.4$ & $2.74 \pm 0.29$ \\
\hline $48 \mathrm{~h}$ after admission & & $26.2 \pm 2.3$ & $22.3 \pm 4.2$ & $1.4 \pm 0.1$ & $28.1 \pm 3.2$ & $3.95 \pm 0.41$ \\
\hline
\end{tabular}

${ }^{\mathrm{a} C o m p a r e d}$ wtih the Survivor group; ${ }^{\mathrm{b}}$ compared with 12 after admission; ${ }^{\mathrm{c}}$ compared with $24 \mathrm{~h}$ after admission. $\mathrm{P}<0.05$, the difference is statistically significant.

the non-MODS group. These indexes were higher at $24 \mathrm{~h}$ after admission than those at $12 \mathrm{~h}$ after admission, and also higher at $48 \mathrm{~h}$ after admission than those at $24 \mathrm{~h}$ after admission. The differences were statistically significant $(\mathrm{P}<0.05)$ (Table III).

Comparisons of ISS, APACHE II score, NF- $\kappa B, I L-6$ and TNF- $\alpha$ levels at different time-points $(12,24$ and $48 \mathrm{~h}$ after admission) between the deceased and survivor. The ISSs, APACHE II scores, NF- $\kappa$ B, IL- 6 and TNF- $\alpha$ levels in the deceased patients at 12,24 and $48 \mathrm{~h}$ after admission were higher than those in survivors. These indexes were higher at $24 \mathrm{~h}$ after admission than those at $12 \mathrm{~h}$ after admission, and also higher at $48 \mathrm{~h}$ after admission than those at $24 \mathrm{~h}$ after admission. The differences were statistically significant $(\mathrm{P}<0.05)$ (Table IV).

Multivariate logistic regression analyses of influencing factors of MODS in patients with severe multiple trauma. The analyses with ISS, APACHE II score, NF- $\kappa$ B, IL-6 and TNF- $\alpha$ levels as the independent variables, and whether MODS occurred as the dependent variable showed that the
Table V. Multivariate logistic regression analyses of influencing factors of MODS in patients with severe multiple trauma.

\begin{tabular}{lccc}
\hline Indexes & P-value & $\begin{array}{c}\text { Odds ratio } \\
(\mathrm{OR})\end{array}$ & $\begin{array}{c}95 \% \text { confidence } \\
\text { interval }(\mathrm{CI})\end{array}$ \\
\hline ISS & 0.823 & 0.919 & $0.659,1.087$ \\
APACHE II score & 0.610 & 0.957 & $0.823,1.316$ \\
NF- $\kappa$ B & 0.463 & 3.562 & $0.314,3.989$ \\
IL-6 & 0.185 & 2.159 & $0.992,4.024$ \\
TNF- $\alpha$ & 0.366 & 1.944 & $0.765,3.566$ \\
\hline
\end{tabular}

ISS, APACHE II score, NF- $\kappa \mathrm{B}$, IL- 6 and TNF- $\alpha$ levels were not the risk factors of MODS in patients with severe multiple trauma, and the differences were not statistically significant $(\mathrm{P}>0.05)$ (Table V).

ROC curves. AUCs of ISS, APACHE II score, NF- $\kappa \mathrm{B}$, IL-6 and TNF- $\alpha$ levels in predicting MODS were 0.598, 


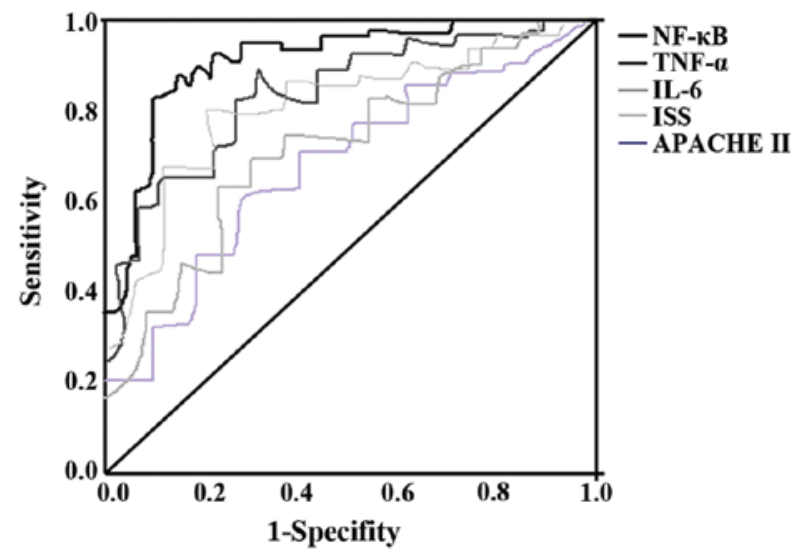

Figure 1. ROC curves of ISS, APACHE II score, NF- $\kappa$ B, IL- 6 and TNF- $\alpha$ levels in predicting MODS.

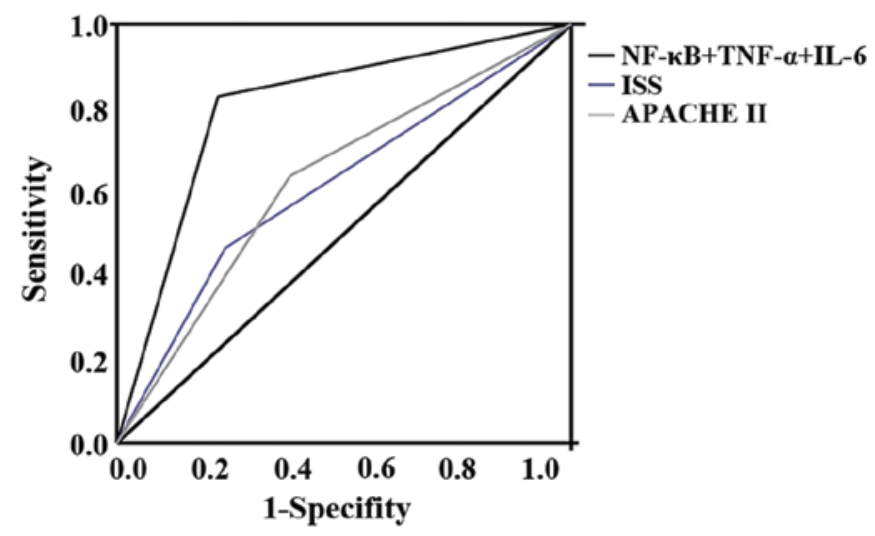

Figure 2. ROC curves of combined detection of NF- $\mathrm{B}$, IL-6 and TNF- $\alpha$ levels and ISS and APACHE II score in predicting MODS.

(95\% CI $=0.483,0.812), 0.664(95 \% \mathrm{CI}=0.614,0.903), 0.796$ $(95 \% \mathrm{CI}=0.699,0.954), 0.835(95 \% \mathrm{CI}=0.713,0.095)$ and 0.803 (95\% $\mathrm{CI}=0.705,0.903)$, respectively; the cut-off values were as follows: ISS $>22$ points; APACHE II score $>14$ points; NF- $\kappa \mathrm{B}$ $>1.20$; IL-6 $>25.1 \mu \mathrm{g} / \mathrm{l}$ and TNF- $\alpha>2.20 \mathrm{ng} / \mathrm{ml}$. The sensitivities were $66.7,75.2,79.3,83.7$ and $86.0 \%$, respectively, and the positive likelihood ratios were 2.12, 2.63, 3.51, 2.98 and 3.53, respectively, at the cut-off values (Fig. 1).

ROC curves of combined detection of NF- $\kappa B, I L-6$ and TNF- $\alpha$ levels and ISS and APACHE II score of patients with severe multiple trauma in predicting MODS. AUCs of ISS $>22$ points and APACHE II score $>14$ points in predicting MODS were $0.598(95 \% \mathrm{CI}=0.483,0.812)$ and $0.664(95 \% \mathrm{CI}=0.614,0.903)$, which were lower than that of combined detection of NF- $\kappa \mathrm{B}$ $>1.20$; IL-6 $>25.1 \mu \mathrm{g} / \mathrm{l}$ and TNF- $\alpha>2.20 \mathrm{ng} / \mathrm{ml}$ in peripheral blood in predicting MODS $(0.853,95 \% \mathrm{CI}=0.659,0.977)$. and the differences were statistically significant $(\mathrm{P}<0.001)$ (Fig. 2).

\section{Discussion}

In the disease or severe trauma, failures of two or more organs in the body consecutively or simultaneously are defined as multiple organ failure (MOF). At present, more and more theories argue that MODS, instead of MOF, is more reason- able and scientific (8). Clinically, acute multiple trauma is a common disease in emergency, often seriously threatening the life of patients. There are also increasingly more studies on severe multiple trauma, but there is a lack of more accurate predictive indexes for severe multiple trauma or MODS (9). After severe trauma, infection or major surgery, the body will exhibit a significant acute inflammatory reaction, thus causing abnormal inflammatory mediator expression levels, among which inflammatory as well as anti-inflammatory mediators are the most common (10). In particular, inflammatory and anti-inflammatory mediators are in a relatively unstable state in patients with severe multiple trauma (11), and the expression levels of anti-inflammatory mediators are enhanced with the increase in inflammatory mediators, showing balance and fluctuation between inflammatory and anti-inflammatory mediators (12). In addition to the expression of inflammatory mediators, more indexes are involved in the regulation process of inflammatory mediators, which can indirectly reflect the degree of inflammatory response (13). Many studies have shown that NF- $\mathrm{NB}$ is an important regulatory factor in the inflammatory response process, which in turn affects the expression disorder of inflammatory mediators. Moreover, $\mathrm{NF}-\kappa \mathrm{B}$ activates the immune system in the body via early activation, exhibiting SIRS (14); continuous attack and multiple organ dysfunctions under stress state result in MODS (15). After activation, $\mathrm{NF}-\kappa \mathrm{B}$ enters neutrophils and monocytes quickly, and specifically binds to gene promoter and enhancer, which is expressed by cell regulatory factors and promotes the synthesis and release of a large number of inflammatory factors after binding and regulation, such as IL-6, IL-8 and TNF- $\alpha$. The most important factors stimulating the synthesis of acute reactive protein in SIRS are IL-6 and TNF- $\alpha(16,17)$.

In this study, the ISS, APACHE II score, NF- $\kappa \mathrm{B}$, IL- 6 and TNF- $\alpha$ levels in the MODS group were higher than those in the non-MODS group. With the prolongation of time, these indexes were increased. The ISS, APACHE II score, NF- $\kappa \mathrm{B}$, IL- 6 and TNF- $\alpha$ levels in the deceased patients were obviously higher than those in survivors. With the prolongation of time, these indexes were increased, and the differences were statistically significant. It can be seen that ISS and APACHE II score, or NF- $\kappa \mathrm{B}, \mathrm{IL}-6$ and TNF- $\alpha$ have great reference significance in the diagnosis of MODS. However, the multivariate logistic regression analyses of influencing factors of MODS in patients with severe multiple trauma showed that the ISS, APACHE II score, NF- $\kappa \mathrm{B}, \mathrm{IL}-6$ and TNF- $\alpha$ levels were not the risk factors of MODS in patients with severe multiple trauma. Besides, the ROC curves of combined detection of NF- $\kappa \mathrm{B}, \mathrm{IL}-6$ and TNF- $\alpha$ levels and ISS and APACHE II score of patients with severe multiple trauma in predicting MODS revealed that AUCs of ISS $>22$ points and APACHE II score $>14$ points in predicting MODS were significantly lower than that of combined detection of NF- $\kappa \mathrm{B}>1.20$. IL- $6>25.1 \mu \mathrm{g} / \mathrm{l}$ and TNF- $\alpha>2.20 \mathrm{ng} / \mathrm{ml}$ in peripheral blood, suggesting that the combined detection of NF- $\kappa \mathrm{B}$, IL- 6 and TNF- $\alpha$ in peripheral blood of patients with severe multiple trauma has important significance in predicting MODS (18).

The pathogenesis and pathophysiological process of MODS are extremely complex, and the states of corresponding inflammatory and anti-inflammatory mediators at different stages of disease are different (19). Maintaining the 
relative balance between inflammation and anti-inflammation in human body is the most critical step in the treatment of MODS. The detection of inflammation-related factors, such as IL-6 and TNF- $\alpha$, can reflect the autoreaction. Moreover, the intervention in $\mathrm{NF}-\kappa \mathrm{B}$ activity can ultimately interfere in the pathogenesis of MODS and improve the prognosis (20).

\section{Acknowledgements}

Not applicable.

\section{Funding}

The present study was supported by the Scientific Research Projects of Health and Family Planning Commission of Sichuan Province, China (grant no. 140088).

\section{Availability of data and materials}

The datasets used and/or analyzed during the present study are available from the corresponding author on reasonable request.

\section{Authors' contributions}

JZ wrote the manuscript and performed EMSA and ELISA.

\section{Ethics approval and consent to participate}

The study was approved by the Ethics Committee of Sichuan Provincial People's Hospital (Chengdu, China) and written informed consents were signed by the patients and/or guardians.

\section{Patient consent for publication}

Not applicable.

\section{Competing interests}

The author declares that he has no competing interests.

\section{References}

1. Fremont RD, Koyama T, Calfee CS, Wu W, Dossett LA, Bossert FR, Mitchell D, Wickersham N, Bernard GR, Matthay MA, et al: Acute lung injury in patients with traumatic injuries: Utility of a panel of biomarkers for diagnosis and pathogenesis. J Trauma 68: 1121-1127, 2010.

2. Davenport R and Brohi K: Fibrinogen depletion in trauma: Early, easy to estimate and central to trauma-induced coagulopathy. Crit Care 17: 190, 2013.

3. Frink M, van Griensven M, Kobbe P, Brin T, Zeckey C, Vaske B, Krettek C and Hildebrand F: IL- 6 predicts organ dysfunction and mortality in patients with multiple injuries. Scand J Trauma Resusc Emerg Med 17: 49, 2009.

4. Matsuda N, Hattori Y, Takahashi Y, Nishihira J, Jesmin S, Kobayashi M and Gando S: Therapeutic effect of in vivo transfection of transcription factor decoy to NF-kappaB on septic lung in mice. Am J Physiol Lung Cell Mol Physiol 287: L1248-L1255, 2004.
5. Moraes LA, Piqueras L and Bishop-Bailey D: Peroxisome proliferator-activated receptors and inflammation. Pharmacol Ther 110: 371-385, 2006.

6. Cuzzocrea S, Pisano B, Dugo L, Ianaro A, Maffia P, Patel NS, Di Paola R, Ialenti A, Genovese T, Chatterjee PK, et al: Rosiglitazone, a ligand of the peroxisome proliferator-activated receptor- $\gamma$, reduces acute inflammation. Eur J Pharmacol 483: 79-93, 2004.

7. Marshall JC, Cook DJ, Christou NV, Bernard GR, Sprung CL and Sibbald WJ: Multiple organ dysfunction score: A reliable descriptor of a complex clinical outcome. Crit Care Med 23: 1638-1652, 1995.

8. Damiani P and Burini G: Fluorometric determination of nitrite. Talanta 33: 649-652, 1986.

9. Dougnac A, Riquelme A, Calvo M, Andresen M, Magedzo A, Eugenin E, Marshall G and Gutiérrez M: Study of cytokines kinetics in severe sepsis and its relationship with mortality and score of organic dysfunction. Rev Med Chil 129: 347-358, 2001 (In Spanish).

10. Stegmaier J, Kirchhoff C, Kanz KG, Mayer V, Landes J, Euler E, Mutschler W and Biberthaler P: Analysis of NF-kappaB nuclear translocation in PMN-neutrophils of major trauma patients in the early post-traumatic period: A pilot study. World J Surg 30: 2142-2151, 2006.

11. Zhao E, Wang L and Wen Q: Fasudil hydrochloride differentiates bone marrow mesenchymal stem cells into neurons via notch signaling. Neural Regen Res 5: 814-819, 2010.

12. Pacary E, Legros H, Valable S, Duchatelle P, Lecocq M, Petit E, Nicole $\mathrm{O}$ and Bernaudin M: Synergistic effects of $\mathrm{CoCl}(2)$ and ROCK inhibition on mesenchymal stem cell differentiation into neuron-like cells. J Cell Sci 119: 2667-2678, 2006.

13. Pacary E, Petit E and Bernaudin M: Concomitant inhibition of prolyl hydroxylases and ROCK initiates differentiation of mesenchymal stem cells and PC12 towards the neuronal lineage. Biochem Biophys Res Commun 377: 400-406, 2008.

14. Collison LW, Workman CJ, Kuo TT, Boyd K, Wang Y, Vignali KM, Cross R, Sehy D, Blumberg RS and Vignali DA: The inhibitory cytokine IL-35 contributes to regulatory T-cell function. Nature 450: 566-569, 2007.

15. Neunaber C, Zeckey C, Andruszkow H, Frink M, Mommsen P, Krettek $\mathrm{C}$ and Hildebrand $\mathrm{F}$ : Immunomodulation in polytrauma and polymicrobial sepsis - where do we stand? Recent Pat Inflamm Allergy Drug Discov 5: 17-25, 2011.

16. Marti L, Cervera C, Filella X, Marin JL, Almela M and Moreno A: Cytokine-release patterns in elderly patients with systemic inflammatory response syndrome. Gerontology 53: 239-244, 2007

17. Li J, Li NP, Gu YF, Yang X, Lu XB, Cong JN, Ling Y, Tang JA, Yuan XY and Wang H: Dynamic activity of NF-kappaB in multiple trauma patients and protective effects of ulinastain. Chin J Traumatol 14: 354-358, 2011.

18. Yadav K, Zehtabchi S, Nemes PC, Miller AC, Azher M, Durkin $\mathrm{H}$ and Sinert R: Early immunologic responses to trauma in the emergency department patients with major injuries. Resuscitation 80: 83-88, 2009.

19. Shih HC, Huang MS and Lee CH: Polymorphonuclear cell priming associated with NF- $\kappa \mathrm{B}$ activation in patients with severe injury is partially dependent on macrophage migration inhibitory factor. J Am Coll Surg 211: 791-797, 2010.

20. Li R, Zijlstra JG, Kamps JA, van Meurs M and Molema G: Abrupt reflow enhances cytokine-induced proinflammatory activation of endothelial cells during simulated shock and resuscitation. Shock 42: 356-364, 2014.

(i) $($ This work is licensed under a Creative Commons Attribution-NonCommercial-NoDerivatives 4.0 International (CC BY-NC-ND 4.0) License. 